\title{
Correction to: Informed consent and informed intervention: SARS-CoV-2 vaccinations not just call for disclosure of newly emerging safety data but also for hypothesis generation and testing
}

Johannes C. Fischer ${ }^{1}$, Albrecht G. Schmidt ${ }^{2}$, Edwin Bölke ${ }^{2 *} \mathbb{0}$, Verena Keitel ${ }^{3}$, Torsten Feldt ${ }^{3}$, Björn Jensen $^{3}$, Noemi F. Freise ${ }^{3}$, Dieter Häussinger ${ }^{3}$, E. Marion Schneider ${ }^{4}$, Derik Hermsen ${ }^{5}$, Detlef Kindgen-Milles ${ }^{6}$, Wolfram Trudo Knoefel ${ }^{7,8}$, Jan Haussmann², Balint Tamaskovics ${ }^{2}$, Christian Plettenberg ${ }^{9}$, Kathrin Scheckenbach ${ }^{9}$, Stefanie Corradini ${ }^{10}$, Jutta Rox ${ }^{1}$, Vera Balz ${ }^{1}$, Kitti Maas², Livia Schmidt ${ }^{2}$, Olaf Grebe ${ }^{11}$, Anja Ehrhardt ${ }^{12}$, Peter Arne Gerber ${ }^{13}$, Matthias Peiper ${ }^{14}$, Bettina Alexandra Buhren ${ }^{2}$, Artur Lichtenberg ${ }^{14}$, Amir Rezazadeh², Wilfried Budach ${ }^{2}$ and Christiane Matuschek ${ }^{2}$

\section{Correction to: Eur J Med Res (2021) 26:87} https://doi.org/10.1186/s40001-021-00558-y

In the original publication of the article [1], the author name Anja Ehrhardt was incorrectly written as Anja Erhardt.

The original article has been corrected.

\section{Author details}

'Institute for Transplantation Diagnostics and Cell Therapeutics, Medical Faculty, University Hospital Dusseldorf, Heinrich-Heine-University, 40225 Düsseldorf, Germany. ${ }^{2}$ Department of Radiation Oncology, Medical Faculty, University Hospital Dusseldorf, Heinrich-Heine-University Dusseldorf, Moorenstr. 5, 40225 Düsseldorf, Germany. ${ }^{3}$ Department of Gastroenterology, Hepatology and Infectious Diseases, Medical Faculty, University Hospital Dusseldorf, Heinrich-Heine-University Dusseldorf, Moorenstr. 5, 40225 Düsseldorf, Germany. ${ }^{4}$ Division of Experimental Anesthesiology, University Hospital Ulm, Ulm, Germany. ${ }^{5}$ Central Institute for Laboratory Diagnostics and Clinical Chemistry, Medical Faculty, Heinrich-Heine University, Düsseldorf, Germany. ${ }^{6}$ Department

The original article can be found online at https://doi.org/10.1186/s40001021-00558-y

*Correspondence: boelke@uni-duesseldorf.de; boelke@med.uni-duesseldorf.de ${ }^{2}$ Department of Radiation Oncology, Medical Faculty, University Hospital Dusseldorf, Heinrich-Heine-University Dusseldorf, Moorenstr. 5, 40225 Düsseldorf, Germany

Full list of author information is available at the end of the article of Anesthesiology, Medical Faculty, Heinrich Heine University, Dusseldorf, Germany. ${ }^{7}$ Department of Surgery and Interdisciplinary Surgical Intensive Care Unit, Medical Faculty, Heinrich Heine University, Düsseldorf, Germany. ${ }^{8}$ Medicine, Department cBITE, Maastricht, The Netherlands. ${ }^{9}$ Department of Otolaryngology-Head and Neck Surgery, Medical Faculty, Heinrich Heine University, Düsseldorf, Germany. ${ }^{10}$ Department of Radiation Oncology, University Hospital, LMU Munich, Munich, Germany. ${ }^{11}$ Department of Cardiology and Rhythmology, Petrus Hospital, Wuppertal, Germany. ${ }^{12}$ Institute of Virology, University of Witten/Herdecke, Witten, Germany. ${ }^{13}$ Medical Faculty, University of Dusseldorf, Düsseldorf, Germany. ${ }^{14}$ Department of Cardiac Surgery, Medical Faculty, University of Dusseldorf, Düsseldorf, Germany.

Published online: 13 September 2021

\section{Reference}

1. Fischer JC, Schmidt AG, Bölke E, Keitel V, Feldt T, Jensen B, Freise NF, Häussinger D, Schneider EM, Hermsen D, Kindgen-Milles D, Knoefel WT, Haussmann J, Tamaskovics B, Plettenberg C, Scheckenbach K, Corradini S, Rox J, BalzV, Maas K, Schmidt L, Grebe O, Ehrhardt A, Gerber PA, Peiper M, Buhren BA, Lichtenberg A, Rezazadeh A, Budach W, Matuschek C. Informed consent and informed intervention: SARS-CoV-2 vaccinations not just call for disclosure of newly emerging safety data but also for hypothesis generation and testing. Eur J Med Res. 2021;26:87. https://doi. org/10.1186/s40001-021-00558-y.

\section{Publisher's Note}

Springer Nature remains neutral with regard to jurisdictional claims in published maps and institutional affiliations. original author(s) and the source, provide a link to the Creative Commons licence, and indicate if changes were made. The images or other third party material in this article are included in the article's Creative Commons licence, unless indicated otherwise in a credit line to the material. If material is not included in the article's Creative Commons licence and your intended use is not permitted by statutory regulation or exceeds the permitted use, you will need to obtain permission directly from the copyright holder. To view a copy of this licence, visit http://creativecommons.org/licenses/by/4.0/. The Creative Commons Public Domain Dedication waiver (http://creativecommons.org/publicdomain/zero/1.0/) applies to the data made available in this article, unless otherwise stated in a credit line to the data. 